\title{
La lectura de la República que hace el primer franquismo: El Noticiero de España como fuente
}

Carlos Pulpillo Leiva

\section{Instituto de Humanidades de la Universidad Rey Juan Carlos}

carlospulpillo@gmail.com

Fecha recepción 15.05.2017 / Fecha aceptación 11.10.2017

\section{Resumen}

El Franquismo se configuró en clara contraposición a lo que la Segunda República había significado para España. Para ello desarrolló importantes campañas propagandísticas con el objetivo de deslegitimar la acción de una República elegida en las urnas. Para la creación de un relato en el exterior contó con el Noticiero de España, un recurso que se editaba en la Jefatura del Estado de Burgos. La misión fundamental era justificar la necesidad del alzamiento que realizaron los militares, debido a que mostraban un régimen anárquico, cruel, anticlerical, represivo, etc. en esencia que atentaba contra lo que significaba lo español en el pensamiento tradicional.

\section{Palabras clave}

Noticiero de España, II República, Franquismo, Propaganda.

\begin{abstract}
Franco's Regime was configured in contrast to what the Second Republic had meant for Spain. It developed significant propaganda campaigns with the objective of delegitimizing the elected Republic. Francoism wanted to create a different narrative abroad, and so published the Noticiero de España, a resource that was edited by the Headquarters of the State of Burgos. Its fundamental mission was to justify the need for the uprising by the military, because they showed an anarchic, cruel, anticlerical, repressive regime, etc. In essence, it went against what the Spanish meant by 'traditional thinking'.
\end{abstract}

\section{Keywords}

Noticiero de España, II Republic, Franco's Regime, Propaganda. 



\section{1.- El Noticiero de España: fuente para el conocimiento del primer Franquismo}

La propaganda durante la Guerra Civil española hay que entenderla como una forma de actuación más en el conflicto. Ambos bandos fueron conscientes de la potencialidad de la propaganda y la construcción de un relato que sustentase lo que estaban consiguiendo por las armas. Demostrando que tan importante era vencer como convencer a la población y otros organismos de un relato que aportase legitimidad al poder emanado de la guerra ${ }^{1}$. El Franquismo, aunque más tarde que la República, configuró unos órganos de prensa y propaganda con el objetivo de tener mayor control y ascendencia sobre la información para difundir una narración concreta de la guerra, de las motivaciones y las consecuencias e influir en una España que también se media a través de las plumas ${ }^{2}$. De este modo, los medios de comunicación fueron usados como una forma de persuasión y movilización de la masa social y, también, de unas ideas encaminadas a la búsqueda de legitimación. Para ello, trabajaron en edificar un discurso propagandístico monocorde y reiterativo para que trascendiese los medios comunicativos y enraizase en la mentalidad colectiva de los ciudadanos del nuevo

1. La propaganda en el contexto de la Guerra Civil española ha sido trabajada con profusión. Algunos trabajos fundamentales al respecto son: F. Sevillano, Propaganda y medios de comunicación en el franquismo (1936-1951), Alicante, 1998; M. Crusells, La Guerra Civil española: cine y propaganda, Barcelona, 2003; A. Pizarroso, "La Guerra Civil española, un hito de la historia de la propaganda", El Argonauta Español, 2, 2005; J.M. Delgado (coord.), Propaganda y medios de comunicación en el primer franquismo (1936-1959), Logroño, 2006; S. Núñez de Prado, Las armas ideológicas de Franco, Madrid, 2013; E. Peral \& F. Sáez (eds.), Métodos de propaganda activa en la Guerra Civil española. Literatura, arte, música, prensa y educación, Madrid, 2015; o los diferentes estudios de A.C. Moreno donde destaca Tiempo de mentiras: el control de la prensa extranjera en España durante el primer franquismo (1936-1945), Teruel, 2016.

2. La Junta de Defensa Nacional organizó un Gabinete de Prensa donde centralizó toda la información. En la dirección situó al periodista Juan Pujol, quien debía estar auxiliado por Joaquín Arrarás. El 24 de agosto de 1936 se configuró la Oficina de Prensa y Propaganda, destinado a organizar toda la información y propaganda, entendidas como un mismo concepto, con importantes cargas adoctrinadoras pero centrados, básicamente en el desarrollo de la contienda. Con la creación de la Junta Técnica del Estado se organizó una sección específica para la Prensa y Propaganda dentro de la Comisión de Cultura y Enseñanza, poniendo al frente en un primer momento al mutilado Millán-Astray y donde colaboró Luis Bolín. Finalmente en enero de 1937 se creó la Delegación de Prensa y Propaganda, con Vicente Gay al frente, que fue donde se configuró el $N d E$. 
Estado. La estrategia que debían inculcar era el uso de mensajes repetitivos, sencillos y fáciles de entender por los interlocutores para afianzar las bases sociales de la nueva España ${ }^{3}$.

Dentro de las diferentes publicaciones que se potenciaron desde la Delegación de Prensa y Propaganda el presente trabajo quiere centrarse en el Noticiero de España (NdE) y la visión que aportó en sus páginas de la Segunda República. La fuente incide en las campañas de desprestigio, deslegitimación y crueldad que la prensa que era afín a los sublevados potenció como idea para justificar el alzamiento del 18 de julio. Premisas que no eran originales pero que se trataban de una serie de eufemismos apoyados a veces en medias verdades que repitiendo hasta la saciedad debían influir en los potenciales lectores. En este caso, la pregunta es ¿dónde reside la importancia del $N d E$ ?

Lo primero que hay que destacar es que el $N d E$ no era una revista, sino más bien un argumentario que se organizó en la misma Jefatura del Estado del Cuartel General de Burgos desde el 4 de septiembre de 1937 (No 1) al 4 de octubre de 1941 (№ 208). La idea de argumentario se notaba en la propia tipología de la fuente, ya que no tenía ni maquetación e impresión profesional, sino que más bien eran unas hojas de texto mecanografiadas con fotografías pegadas con adhesivo en las mismas páginas. Por lo tanto, la fuente es un texto argumentativo para dar soporte a otras publicaciones más que en una revista en sí. Un texto que tiene como objetivo la persuasión de los potenciales lectores ${ }^{4}$.

El origen del NdE ha de entenderse en el interés de la naciente España de Franco por el control de los flujos informativos hacia el exterior ${ }^{5}$. En los primeros meses de la Guerra Civil era el bando republicano quien estaba ganando la batalla del relato. Así, el malagueño Luis A. Bolín, como jefe de la Oficina de Prensa del Cuartel General, fue quien desarrolló los mecanismos del despótico control que se hizo sobre la información de los corresponsales extranjeros a través de los oficiales de prensa ${ }^{6}$. Según el falaz personaje de él partió la idea de crear

3. Sevillano, Propaganda y medios... op. cit. 55 y ss.

4. Persuasión entendida como un proceso comunicativo en el que se pretende promover una dependencia interactiva entre emisor y receptor mediante la formación, reforzamiento o modificación de la respuesta del receptor. A. Pizarroso, "La historia de la propaganda: una aproximación metodológica", Historia y Comunicación Social, 4, 1999, 146.

5. El Franquismo tenía fácil el control informativo hacia el interior dado que controlaba los medios para el control y la supervisión de sus fronteras. Pero el problema lo tuvo en la propaganda exterior ya que en un principio no consideró necesario llevar a cabo una defensa de sus tesis, a medida que pasaba el conflicto cayó en la cuenta de la necesidad que legitimar la acción de las armas a través de la palabras. Para ello, puso en marcha un proceso persuasivo y legitimador a través de los países donde tenía legaciones exteriores. El tema puede ampliarse con el magnífico estudio de A.C. Moreno, Tiempo de mentiras: el control de la prensa extranjera en España durante el primer franquismo (1936-1945), Teruel, 2016.

6. En la orden del 19 de julio de 1937 se creó la figura del Oficial de Prensa que teóricamente eran los «encargados de la vigilancia periodística y de atender a las personalidades extranjeras que deseen visitar la España liberada». Pero más bien su acción se basó en coartar la libertad informativa e imponer la censura a los corresponsales extranjeros como se venía haciendo desde los inicios de la guerra. L. Arias, "El papel del oficial de prensa en el Bando Nacional: Gonzalo de Aguilera Munro”, Investigaciones Históricas, 33, 2013, 209-2014. 
un servicio de prensa que «asesorase» a estos corresponsales y, además, trabajase en generar la creación de una imagen atractiva y «verdadera» de los actos de los soldados en campaña y, además, de la organización del «nuevo Estado» ${ }^{7}$. En estas afirmaciones hay que manifestar la importancia de la creación de un argumentario como el NdE, dado que contribuyó claramente a esa idea que manifestaba Bolín, es decir, fomentar la imagen exterior de la España de Franco a través de la creación de unos contenidos difundidos entre las diferentes legaciones extranjeras. En el organigrama de la Jefatura del Estado como jefe de Prensa extranjera actuó Jesús Pabón ${ }^{8}$, quien dio un impulso y buenas ideas iniciales a la creación de la fuente; aunque no puede desdeñarse el grupo de colaboradores que tuvo, los cuales fueron fundamentales en el $N d E$, como Melchor Fernández Almagro ${ }^{9}$, Luis María de Lojendio ${ }^{10}$, Manuel Torres López ${ }^{11}$ o Manuel García Blanco ${ }^{12}$ entre otros.

La fuente estaba organizada en las siguientes secciones: Colaboración, Réplicas, Operaciones militares, Movimientos militares, Acontecimientos internacionales, Notas financieras, Testimonios; Reportajes y Las armas y las letras. A través de ellas se quería asentar las bases ideológicas del naciente Estado. Desde él fueron difundiéndose las premisas fundamentales acerca de la implantación del Franquismo, sobre la guerra, sobre la política internacional, etc., pero también argumentos que desprestigiasen a la República como medio de legitima-

7. L.A. Bolín, España, los años vitales, Madrid, 1967, 197.

8. Jesús Pabón, historiador y periodista que fue diputado por la CEDA durante la Segunda República. Estallada la guerra consiguió esconderse y huir a la zona sublevada colaborando en el servicio de propaganda del nuevo gobierno. Posteriormente, fue cercano al círculo de don Juan. C. Seco, "Jesús Pabón. El hombre, el político, el historiador", Estudios de Historia Moderna y Contemporánea. Homenaje a D. Jesús Pabón (I). Madrid, XXVII, 112, 1978, 5-152.

9. Melchor Fernández Almagro, historiador y periodista relacionado con los intelectuales madrileños del Café Jorge Juan o Café Lyon. Con el estallido de la guerra se trasladó a la zona controlada por el bando nacional incorporado a la colaboración en Prensa y Propaganda. Finalizado el conflicto adquirió colaboró con medios como ABC o La Vanguardia. Fue miembro de la Real Academia de la Lengua España y de la Real Academia de la Historia. C. Viñes, "Melchor Fernández Almagro y la cultura de su época (esbozo biográfico)”, Homenaje a D. José Luis Comellas, Sevilla, 2000, 237-255.

10. Luis María de Lojendio personaje polifacético ya que fue abogado, escritor, pintor terminando por ser abad del Valle de los Caídos. Durante la guerra dirigió la Oficina de Prensa del Cuartel General y fue portavoz para la prensa extranjera de las noticias del conflicto. Un acercamiento biográfico puede verse en: J.B. Lojendio, "Vida y obra de Luis Ma de Lojendio", Ondare, 27, 2009, 151-192; o recientemente J.M. Fernández: "Luis María de Lojendio, portavoz de la política exterior española en la Guerra Fría. Un viaje personal desde el último franquismo", Hispania Nova, 14, 2016, 213-228.

11. Manuel Torres López, jurista que desde joven actuó dentro de asociaciones católicas de estudiantes dependiente de la ACNP. Fue miembro de la CEDA y, en la guerra, subdelegado y jefe de Prensa y Propaganda de Salamanca. Posteriormente ocupó otros cargos políticos de relevancia hasta su separación del Franquismo en los años cincuenta. I. Peiró y G. Pasamar, Diccionario Akal de Historiadores Españoles Contemporáneos (1840-1980), Madrid, 2002. 628-629.

12. Manuel García Blanco, catedrático universitario de Historia del Español que sustituyó a Unamuno en Salamanca. Colaboró con artículos en la prensa de los sublevados. Terminada la guerra continuó con su actividad universitaria. Un acercamiento biográfico se encuentra en Thesaurus, XXI, 1, 1966, 241-242. 
ción. En este sentido, los propagandistas del $N d E$ van a utilizar diferentes técnicas propagandísticas con el objetivo de que su mensaje fuese los más claro posible para los diferentes interlocutores ${ }^{13}$. Todo ello, con el objetivo último de aportar ideas y argumentos a los lectores que justificasen la necesidad del alzamiento militar y, por ende, contribuir a la legitimización de la España de Franco.

No obstante, lo realmente interesante del $N d E$ era que se realizaba para ser enviado a las legaciones españolas en el exterior. En España solo se quedaba un ejemplar que era presentado ante el mismo jefe del Estado, por lo tanto, era un texto que tenía un nulo recorrido por la prensa española. Llegado a los organismos exteriores de la diplomacia franquista los artículos eran seleccionados por las secciones de prensa y, adaptándolos a los potenciales lectores, reproducidos literalmente en revistas editadas por la legación del correspondiente país. Ejemplos claros de ellos son las revistas: Orientación Española de Buenos Aires, Spain de New York, Spain de Londres o L'Occident de Paris ${ }^{14}$.

\section{2.- La República como cenit de la decadencia española}

La Segunda República en España se configuró como un periodo bisagra entre la decadente monarquía de Alfonso XIII y la Guerra Civil que conllevó la dictadura. A pesar de sus escasos años de vigencia es fundamental para comprender la historia española posterior. El Franquis-

13. En las páginas del $N d E$ se observa cómo son usadas diversas técnicas propagandísticas tales como: el empleo de estereotipos, la sustitución de nombres, la selección de hechos, la mentira descarada, la repetición u orquestación, la afirmación vehemente de argumentos, señalar claramente al enemigo, la alusión a la autoridad, la simplificación de los hechos o la exageración. J.A.C. Brown, Técnicas de persuasión: de la propaganda al lavado de cerebro, Madrid, 2004, 25-28.

14. Para conocer la acción propagandística en el exterior en los países a los que se hace referencia puede consultarse la obra coordinada por A.C. Moreno, El ocaso de la verdad: propaganda y prensa exterior en la España franquista (1936-1945), Madrid, 2011. Asimismo, para el caso concreto de Gran Bretaña pueden consultarse los trabajos de E. Moradiellos, "Una guerra civil de tinta: la propaganda republicana y nacionalista en Gran Bretaña", Sistema, 164, 2001, 69-97); y de H. García, Mentiras necesarias. La batalla por la opinión británica durante la Guerra Civil, Madrid, 2008. Para Francia pueden consultarse los artículos de A.C. Moreno, "La propaganda franquista en Francia durante la Guerra Civil (1936-1939)", A. Bullón de Mendoza \& L.E. Togores, La República y la Guerra civil setenta años después, 2, Madrid, 2008, 819-833; y "Delegaciones y oficinas de prensa y propaganda en el extranjero durante el primer franquismo: el caso francés (1936-1942)", Studia historica: Historia Contemporánea, 25, 2007, 265-301. Para Estados Unidos, hay que destacar nuevamente a A.C. Moreno, "Proyección propagandística de la España franquista en Norteamérica (1936-1939), Hispania Nova, 2009; o el trabajo de S. García, "Estados Unidos y la Guerra Civil Española”, V. Sánchez-Biosca (ed.) España en armas. El cine de la Guerra Civil Española, Valencia, 2013, 4551. Finalmente, para Argentina pueden consultarse los trabajos de F. Montiel, "Ediciones propagandística españolas en Argentina durante la Guerra Civil y el primer franquismo: la labor de José Ignacio Ramos", Kamchatka, 7, 2016, 35-57; y A.N Ferreyra, "La acción propagandística a favor del Franquismo durante la Guerra Civil Española: la actuación de Juan Pablo de Lojendio en Buenos Aires (1936-1939), Páginas, 8, 16, 2016, 123-140. 
mo montó todo un relato contrario a la República ya que fundamentó su legitimidad en la guerra y también en una divergente oposición de lo que la República significó en cuanto a cambio social, político, económico o cultural.

Como se ha expuesto el $N d E$ fue una fuente importante en cuanto a la fundamentación de ese relato en el exterior. En la batalla propagandística había que atacar y desprestigiar a la República para aportar una imagen en la que prevaleciesen conceptos como el caos, destrucción, crueldad, anticlericalismo, etc., en la memoria de los lectores de las revistas que recibían los contenidos del $N d E$. Aunque en la perspectiva ideológica del Franquismo la decadencia de España venía del denostado siglo XIX, para ellos la República significaba el necesario punto y final de una España decadente que, sobre los cimientos de una guerra, debía alumbrar un nuevo periodo de verdadero y sincero patriotismo español ${ }^{15}$.

\subsection{4 de abril de 1931: advenimiento de la República}

Los autores del NdE van a intentar siempre relacionar la idea de República con momentos de caos políticos y sociales acaecidos en otros momentos recientes de la historia española. De este modo, van a intentar relacionar la corriente política republicana con las diferentes organizaciones políticas y sindicales que en el periodo alfonsino habían realizado reivindicaciones o, incluso, levantamientos contra el Estado como en 1917 o en 1930. Ello lo van a fundamentar en la idea que los republicanos representaban una minoría dentro del Estado, por lo que no tenían suficiente fuerza para poder derrocar a la Monarquía e instaurar la República a España ${ }^{16}$. Para Salvador Minguijón los republicanos estaban resentidos y requemados por sus pretensiones de poder malogradas, por lo que buscaron la alianza con organizaciones y partidos obreros de carácter revolucionario con la idea de llevar a cabo la implantación del sistema político que deseaban ${ }^{17}$. Minguijón, educado políticamente en la ACNP (Asociación Católica Nacional de Propagandistas) y en el pensamiento tradicional español, lo que quería hacer era asociar los términos de republicano y revolución como medio para conseguir el fin de acabar con la Monarquía. No obstante, en su pluma también se le olvida mencionar la situación decadente en la que había entrado España en los últimos años del reinado de Alfonso XIII que había degenerado en sendas dictaduras.

15. El sentimiento nacionalista fue un elemento doctrinal común y unificador entre los sublevados. Por lo tanto, fue un argumento recurrente para usarlo en contraposición al "patriotismo republicano» que, en su ideario, no defendía la independencia y soberanía de la nación dada la relación con la Rusia Comunista. Nacionalismo defendido como inherente a un sentimiento católico presente en todo español. X.M. Núñez Seixas, ¡Fuera el invasor! Nacionalismos y movilización bélica durante la guerra civil española (1936-1939), Madrid, 2006, 180-181.

16. La oposición republicana tenía en los años finales de la Dictadura de Primo de Rivera un cierto peso en la sociedad y en círculos intelectuales, los cuales fueron perseguidos y represaliados por el Régimen. J. Chaves, "Oposición política a la monarquía de Alfonso XIII. José Giral y los republicanos en la Dictadura de Primo de Rivera", Hispania, LXXVI, 252, 2016, 159-187.

17. S. Minguijón, "La cuestión española.- Antecedentes", Noticiero de España, 37, 28 de mayo de 1938. 
Con estas premisas de partida evidentemente los autores del $N d E$ van a cuestionar los resultados y la validez del proceso electoral del 12 de abril de 1931, ya que lo califican de sin sentido debido a las terribles consecuencias que tuvo para España. Además de argumentar que tal cambio político no era legal por medio de unas elecciones municipales. No obstante, se añade que, incluso dando por válido que los republicanos tenían una mayor representatividad en las ciudades, calificadas de núcleos revolucionarios, la realidad fue que los monárquicos consiguieron un mayor número de votos, por lo que les era incomprensible la proclamación republicana. En consecuencia, para los propagandistas del NdE resulta incomprensible la actitud que Alfonso XIII tomó porque teniendo una mayoría que lo aceptaba como Rey decidió dejar el país a la suerte de las «hordas», sin oponer ningún tipo de resistencia ${ }^{18}$. Por tanto, traicionó al país y fue algo que el Franquismo siempre tuvo presente ${ }^{19}$. En el NdE fue un personaje como el Conde de Romanones, que había tenido cargos importantes durante el periodo alfonsino, quien criticó con dureza la actitud del Rey:

El 14 de abril del 31, no el resultado de las elecciones municipales, sino un estado ambiente bien acusado, hizo creer que España quería cambiar de régimen y cambió sin que se produjera la más pequeña resistencia porque uno a quien yo conozco mejor que nadie, fue el encargado de desplegar la bandera blanca, aún le tiembla la mano... ${ }^{20}$

Aceptada la realidad de la implantación de la República el 14 de abril de 1931, ¿qué supuso su llegada para el país? Como se ha manifestado anteriormente se focalizó en la idea de caos y la ruptura del orden tradicional español. Destacando que desde su instauración comenzó en España un proceso anárquico que, aunque posteriormente mejorado bajo los gobiernos de Lerroux, se recrudeció con el triunfo del Frente Popular ${ }^{21}$. El hecho que está presente en la memoria de los autores del $N d E$ para realizar esta crítica desde los orígenes de la República fue el anticlericalismo desarrollado en mayo de 1931 en Madrid. En la conciencia católica de muchos de ellos, la quema de los conventos tuvo un impacto fundamental para confirmar su desapego a la República.

Raimundo Fernández-Cuesta aporta otros argumentos para explicar el caos republicano. Para el madrileño el problema que tuvo la República era que los partidos republicanos no tenían un verdadero programa de gobierno, sino un ansia renovadora con la que engañó al ingenuo pueblo español con la posibilidad de sanear a la sociedad española. FernándezCuesta obvia información acerca del importante peso del pensamiento y la presencia del republicanismo en épocas anteriores y, además, evitando mencionar reuniones republicanas

18. S. Minguijón, “La cuestión española.- Antecedentes”, Noticiero de España, 37, 28 de mayo de 1938.

19. Hay que hacer referencia al escueto texto que el NdE recogió de la muerte de Alfonso XIII, donde hace más referencia a las acciones que el Estado había organizado para conmemorarlo que a la propia figura del depuesto monarca. A. Reverte, "La muerte de Alfonso XIII", Noticiero de España, 179, 8 de marzo de 1941.

20. Conde de Romanones, "Los imperdonables", Noticiero de España, 76, 25 de febrero de 1939.

21. S. Minguijón, “El alzamiento era inevitable”, Noticiero de España, 51, 3 de septiembre de 1938. 
como la de San Sebastián, en agosto de 1930, donde se configuró un programa de acción republicano renovador para España.

No obstante, Fernández-Cuesta parte de la idea, a diferencia de Minguijón, de que en España hacía falta una renovación del Estado debido a los motivos que auspiciaban a la decadente Monarquía. Aunque añade que los políticos, influenciados por masones y comunistas, terminaron engañando y aprovechándose del pueblo que había apoyado su llegada:

Por desgracia, bien pronto los hechos vinieron a echar un jarro de agua fría, en aquellas ilusiones, nacidas de los más puros y limpios anhelos populares. Una política sectaria, rencorosa, se convirtió en norma de conducta, masones y marxistas empezaron a campar por sus respetos, libres de toda traba, y una constitución que, en rigor de verdad, jamás llegó a cumplirse, revistió de apariencias legales el Estado más antinacional que jamás tuvo España ${ }^{22}$.

Este argumento también es importante, ya que aparte de deslegitimar los orígenes de la República los propagandistas también querían focalizar la idea de que, aunque embaucaron a la población para la llegada de la República, estos políticos terminaron engañando nuevamente al pueblo porque no se llegaron a cumplir ninguna de las premisas que defendían.

Por lo tanto, con argumentos como estos el $\mathrm{NdE}$ deslegitima el origen republicano y comienza a sembrar una semilla en la mente de los lectores acerca de la idea de ¿cómo un Régimen que llegó con engaños y caos podía ser legítimo?; lo que lleva a otra pregunta ¿era legitimo levantarse contra él?

\subsection{Los bienios republicanos: uno terrible y otro... un poco menos}

Los autores del $N d E$ analizan de manera diferente los dos bienios republicanos, ya que en la configuración de su relato dedican mayor número de páginas a la descripción de las «negativas acciones» realizadas por el gobierno de izquierdas del primer bienio; mientras que trata de forma «más benévola» el segundo con la omisión de datos. Mientras que, del gobierno de Azaña, emanado de las elecciones del 28 de junio de 1931, va a continuar ahondando en las ideas anteriores, más si cabe con cuestiones prácticas focalizadas en la "pésima» gestión política, las reformas de carácter partidista y la conflictividad social que terminaba atentando contra la religión. Además, utilizando la omisión, como técnica propagandística, cuando no hace referencias a la Sanjurjada ${ }^{23}$. Cuando comenta los gobiernos de Lerroux básicamente se va a centrar en la sublevación de Asturias de 1934 y sus consecuencias.

Centrándose en el primer bienio republicano, sí que van a describir con carácter peyorativo alguna de las reformas que el Gobierno realizó:

22. R. Fernández Cuesta, “...la idea que nos mueve”, Noticiero de España, 45, 23 de julio de 1938.

23. La única referencia a este levantamiento viene en un breve acercamiento bibliográfico que se hace a la figura del General donde lo único que se expone es que este movimiento fracaso. A. Palacio, "El General Sanjurjo", Noticiero de España, 136, 11 de mayo de 1940. 
1.- En la descripción de la Constitución de 1931 lo que quisieron demostrar fue que el texto no fue consensuado por la mayoría de los españoles, que no recogía las verdaderas aspiraciones de la sociedad o que nació neutralizada en su eficacia de derechos individuales y políticos por la Ley para la Defensa de la República. Una argumentación que va a estar centrada en intentar desacreditar la Carta Magna con afirmaciones como que a lo largo de los años en los que estuvo vigente los políticos republicanos que la habían votado y defendido en el Parlamento no la respetaban y se la saltaban con el objetivo de perpetuarse en el poder ${ }^{24}$.

Asimismo, para ahondar en el desprestigio también recurre a manifestaciones de personajes socialmente reconocidos como, por ejemplo, José Ortega y Gasset que, aunque la había auspiciado previamente, cambió su pensamiento para criticar e intentar hacer rectificar a la República y el $N d E$ utiliza frases suyas como «(...) las fórmulas triunfantes de la Constitución (...) han hecho de ella una Constitución lamentable, sin pies ni cabeza ni el resto de materia orgánica que suele haber entre los pies y la cabeza» ${ }^{25}$. Usar este tipo de ideas emanadas de autores socialmente reconocidos significaba intentar aportar una mayor legitimidad a los argumentos que se exponían en contra de la Constitución, pero, por el contrario, nunca se analizó el avance que supuso la misma ${ }^{26}$.

2.- El estamento militar sufrió en estos primeros años una importante reforma, la cual contribuyó a generar el desafecto de muchos militares hacia la República y a dar contenido a los africanistas que se alzaron el 18 de julio ${ }^{27}$. Las principales críticas fueron hacia la propia gestión política porque ellos observaban que no se potenciaba a los mejores militares, curtidos en batalla y con experiencia en la defensa de la Patria en Marruecos, mientras que por el contrario favorecían a los que habían sido formados en las escuelas militares, es decir, los que han entrado por la óptica del «nuevo Estado». Por otro lado, también critica la reducción de los efectivos militares o la creación del cuerpo de suboficiales ${ }^{28}$. Asimismo, un aspecto que fue claramente criticado fue el cierre de la Academia Militar de Zaragoza, debido a la relación que la institución tenía con el general Franco, quien había sido su director ${ }^{29}$.

24. S. Minguijón, “La cuestión española.- Legalidad Republicana”, Noticiero de España, 75, 18 de febrero de 1939 .

25. Minguijón, “La cuestión española...”, op. cit.

26. Ortega fue uno de los firmantes en 1931 del Manifiesto al Servicio de la República, siendo una de las imágenes de apoyo con su Delende est monarchia. Sin embargo, su desapego a la República llegó pronto con el artículo "Un Aldabonazo", donde ya destacaba que la idea de la República no está aquello que se estaba construyendo en España. Ortega fue el primer desertor prestigioso del nuevo Régimen. Acción con una tremenda potencialidad propagandística que no obviaron los apologetas del naciente Franquismo. A. Trapiello, Las Armas y las Letras. Literatura y Guerra Civil (1936-1939), Barcelona, 2011, 89-98.

27. Las reformas militares granjeó un importante descontento entre los militares dada la reducción de efectivos, la Ley de retiro, la supresión de organismos el sometimiento del ejército al poder civil o la derogación de la Ley de jurisdicciones de 1906. De estas ideas, salió la idea defendida por la derecha política de que Azaña quería acabar con el ejército más que llevarlo a una mejora necesaria acorde a los tiempos.

28. L.M de Lojendio, Operaciones militares de la guerra de España (1936-1939), Barcelona, 1940, 617.

29. J. del Rio Sainz, "Vida de un héroe", Noticiero de España, 5, 2 de octubre de 1937. 
La conclusión que los autores extraen de ello es que le República atacó desde sus orígenes a aquellos que estaban preparados para salvar y defender a la patria. Por lo tanto, argumenta que los dirigentes republicanos estaban impregnados de un «antimilitarismo rabioso», argumentaciones que están presentes en textos de Lojendio.

3.- La religión también fue un hilo argumental importante en el naciente Franquismo ${ }^{30}$. Más si cabe cuando lo que quiere es potenciar la dicotomía con los republicanos calificándolos de que realizaron una política completamente anticlerical. En este sentido, se quiere conectar con la conciencia católica de los potenciales lectores de las revistas que recibían artículos del $N d E$. La idea que la fuente quería manifestar era que la política de laicización republicana tenía como objetivo erradicar completamente el catolicismo de España. Para ellos, la manifestación clara de estos intereses estaba en la propia Constitución de 1931 con los artículos 26 y 27, ya que supusieron, por un lado, un ataque contra el sustento que el clero tenía en España y a la Órdenes religiosas y sus bienes; mientras que el otro mencionando la libre conciencia y la laicización de los cementerios suponía dejar al «pueblo» sin una guía que influyese en sus conciencias ${ }^{31}$. A todo ello, además, hay que mencionar la crispación en las calles, los incendios de iglesias y conventos tanto el mayo madrileño de 1931, que con el Frente Popular que desembocaron en lo días tristes de la expansión anticlerical de la revolución que tuvo lugar en los comienzos del conflicto ${ }^{32}$.

4.- Un tema que tenía una simbiosis con la Iglesia, como institución, era la educación ${ }^{33}$. La República fue consciente de la necesidad de implementar el sistema educativo para poder crear ciudadanos republicanos. Pero, los propagandistas del NdE vieron en la gestión educativa un «virus», tanto comunista como revolucionario, que afectaba a los estudiantes y que, posteriormente, era difícil de sanar. Un germen basado en dos modelos educativos: por un lado, la Institución Libre de Enseñanza definida como:

30. La Iglesia como institución fue una de las que más perjudicadas se sintió con la República, dado que perdía los privilegios que históricamente había tenido. Ello llevó a que con la guerra definitivamente diese un fundamental aporte ideológico a los sublevados ya que éstos defendían un modelo de país donde el sentimiento y componente religioso tenía un espacio social concreto e influyente.

31. S. Minguijón, "La política religiosa”, Noticiero de España, 47, 5 de agosto de 1938.

32. Ese anticlericalismo estuvo patente a lo largo de muchos de los números del $N d E$, cuando expone tanto el expolio al que fueron sometidas los edificios religiosos, aportando abundante documentación gráfica, como por las vejaciones que los religiosos tuvieron que sufrir.

33. La educación fue uno de los temas candentes en los cambios de la República ya que con ella se quería crear un nuevo modelo educativo basado en fomentar la creación de centros educativos y la difusión de la escolarización. Sin embargo, las grandes críticas por parte del Franquismo llegaron por el cambio en el modelo educativo en el que la religión dejaba de tener un peso específico. Ello, en su parecer, despojaba a los alumnos de unas de las bases sobre la que se debía cimentar la españolidad. 
(...) un movimiento de inteligencia, protestatario, revolucionario, antinacional, en suma, que hábilmente fue apoderándose de los resortes del Estado en materia de educación y cultura, creándose por estos medios, al lado de algunos técnicos preciables, muchos valores falsos intelectuales, cuya característica (...) era coincidir en un profundo desconocimiento de la tradición espiritual de España y en una negación absoluta de todos sus valores ${ }^{34}$.

Por otro lado, la Escuela Moderna de Francisco Ferrer que la describió como un vivero de anarquistas y revolucionarios. El problema de esta educación, para los propagandistas del $N d E$, era que se potenciaba un tipo de «educación popular», que generaba hombres revolucionarios y en el que la religión estaba fuera de los programas educativos. En sentido, los autores atacan los procesos de laicización que tuvo la escuela republicana por el impacto negativo en la conciencia española con acciones como la retirada de los crucifijos de las escuelas, la prohibición de la docencia religiosa o de la acción de las Órdenes y Congregaciones en este ámbito ${ }^{35}$.

En opinión de Fernández Almagro legislar contra la religión en las escuelas fue lo que alimentó un ambiente revolucionario, el extremismo político y un falso ambiente científico que corrompió la verdadera familia, el matrimonio, fundamentando el amor libre, etc. es decir, rompiendo con la moral de las personas. Para el autor granadino esta educación estaba en la base de las turbas que llevaron a cabo la revolución en los primeros momentos de la Guerra Civil:

(...) unos años de escuela laica en España, infiltrada de marxismo y anarquismo, explican más que suficientemente la intervención de muchachos y mozalbetes en las turbas que son sus saqueos, incendios, profanaciones y violencia de toda índole, han preludiado la revolución roja que la espada de Franco ha frustrado para salud de todos ${ }^{36}$.

5.- Social y laboralmente, la acción política que más afectó a las clases conservadoras terratenientes fue la Reforma Agraria, dado que venía a romper no solo con la tenencia de la tierra en España sino también con un sistema de relaciones sociales que estaban profundamente arraigados en determinadas zonas ${ }^{37}$. Para la España de Franco esta significó el rencor

34. C. Clavería, "El primer Gobierno de la nueva España. Y Biografías", Noticiero de España, 23, 5 de febrero de 1938.

35. M. Torres López, "Se rectifica la legislación sectaria de la República", Noticiero de España, 35, 14 de mayo de 1938.

36. M. Fernández Almagro, "La educación roja del pueblo", Noticiero de España, 9, 30 de octubre de 1937.

37. La ruptura social de la Reforma Agraria entre terratenientes y pequeños propietarios y jornaleros significó un importante agravamiento de las relaciones en contextos locales desarrollando periódicos conatos conflictivos con ocupaciones de fincas o, en el caso de los propietarios, dejando las fincas baldías. Esta aunque afrontada con un espíritu reformista necesario en el campo español supuso una ruptura social, laboral y económica en el campo español. Para ampliar esta cuestión consultar la clásica obra de E. Malefakis, Reforma agraria y revolución campesina en España (Madrid, 2001), aunque los avances importantes en los últimos años se han realizado con estudios de carácter local. 
que la República tenia hacia la aristocracia, a los cuales les confiscó casi por completo sus fincas y las vendió en lotes de tierra. Para Mariano Sebastián esta política no consiguió, como pretendía, la creación de nuevos propietarios, ni tampoco una nueva clase media que fuese el sustento social básico de la naciente República. Por ello, el relato que caló de la Reforma fue que supuso un verdadero colapso para la economía de las zonas rurales españolas. Ahondando en el descrédito e ineptitud del político republicano ${ }^{38}$.

Finalmente, pusieron de relieve que la «imposición» de toda esta política durante el primer bienio fue a través del caos, la injusticia, el abuso de poder por los sectores radicales del gobierno, la falsedad ante una legislación que defienden y no cumplen, etc. ${ }^{39}$ A pesar de ello, deja la idea de conflictividad a modo amplio sin entrar a detallar enfrenamientos concretos como, por ejemplo, el acaecido en Casas Viejas.

La victoria de las derechas en las elecciones de noviembre de 1933 hizo que la República pasase a una reorientación de posiciones más conservadoras. Por este hecho, aunque no deja de ser «la malvada» República, los autores del NdE no la atacan con la misma contundencia que al primer bienio como se ha expuesto anteriormente. Ello se deriva a la participación política que algunos de los principales autores de la publicación tuvieron durante la República en general y en este periodo en particular. Jesús Pabón, uno de los principales promotores del $N d E$, fue diputado por la CEDA (Confederación Española de Derechas Autónomas) en las elecciones de 1933 y posteriormente reelegido en 1936 otros personajes, e incluso el propio Franco, también tuvieron relaciones con este partido que aglutinaba la derecha posibilista en la República.

Es más, en determinados momentos la victoria conservadora en las elecciones de 1933 se apreció como una salvación que intentó frenar las políticas del bienio anterior y recuperar, levemente, la esencia y tradición española. Por lo tanto, fundamentan la idea de que esta victoria electoral fue a consecuencia de las erróneas políticas que había desarrollado gobierno de Azaña ${ }^{40}$. Por tanto, aunque el Franquismo fue antirrepublicano y contrario al sistema de partidos, en la fuente se tuvo una cierta consideración a este periodo, sobre todo a la CEDA que representaba Gil-Robles. El NdE manifiesta de la misma que era «(...) un partido poderoso que acató el régimen republicano y lo sirvió con lealtad. Tenía un programa social de inspiración católica, en el cual se consignaba, entre otras cosas, una justa distribución de la tierra con la creación de pequeños patrimonios familiares (...)» ${ }^{41}$. Asimismo, Minguijón manifestaba que supo aglutinar la opinión de personas desencantadas con el primer periodo republicano y que buscaba nuevamente las raíces de la verdadera España.

38. M. Sebastián, "La riqueza agrícola en ambas zonas españolas (I)”, Noticiero de España, 26, 26 de febrero de 1938.

39. L.M. de Lojendio, "El mito de la República liberal", Noticiero de España, 22, 29 de enero de 1938.

40. M. Sebastián, "La riqueza agrícola en ambas zonas españolas (I)", Noticiero de España, 26, 26 de febrero de 1938.

41. S. Minguijón, “La cuestión española.- Antecedentes”, Noticiero de España, 37, 28 de mayo de 1938. 
Sin embargo, a lo que los autores del NdE dieron mayor importancia fue al levantamiento de Asturias y Cataluña en octubre de $1934^{42}$. Defendido como una sublevación organizada a consecuencia de la no aceptación de la derrota de las izquierdas en las elecciones de 1933; a lo que se añade el tema del descrédito de que el Partido que había sido más votado, la CEDA, no tuvo opción de formar gobierno; y por la llamada de Lerroux a tres ministros cedistas para su gobierno de $1934^{43}$. Aquí, nuevamente, va a intentar relacionar el caos con los sectores republicanos de izquierdas, alegando que esta revolución fue llevada a cabo por los mismos hombres que durante la guerra defendieron la legalidad republicana y la democracia. El NdE achaca la culpa de este movimiento a «(...) las diferentes organizaciones societarias de tipo marxista o anarquista, y por el separatismo vasco y catalán ${ }^{44}$. No obstante, en esta acción destacaron la figura de Franco, ya que había que contribuir a su hagiografía, cuando lo postula como la persona fundamental a la que acudió el ministro de Guerra Diego Martínez Hidalgo para hacer frente a la sublevación. El NdE pondera que Franco fue el vencedor del conflicto y obvia la importante participación en el control de Asturias que tuvo el general López Ochoa ${ }^{45}$.

Una Revolución que relacionaron directamente con el Frente Popular, así surge en la fuente la pregunta acerca de ¿qué legitimidad tiene el gobierno frentepopulista cuando fueron ellos fueron los que se rebelaron contra el poder republicano en el 34? La contestación es obvia. El régimen del Frente Popular no tiene ninguna legitimidad porque se sublevó contra el poder legalmente establecido y quiso realizar una revolución de carácter comunista en el suelo español. Esta revolución demuestra, para el $N d E$, que la izquierda no iba a consentir otra derrota en un proceso electoral y se aprovechó de unas fraudulentas elecciones y de la debilidad del presidente Portela Valladares para imponer un régimen que presagiaba el conflicto posterior. Evidentemente la importancia que tuvo la corrupción dentro de los últimos gobiernos de Lerroux fue completamente omitida por la fuente, para dar mayor importancia a la tesis de golpe preparado por la izquierda.

\subsection{Frente Popular: el camino hacia la guerra}

El Franquismo fundamentó el origen de su dictadura en mostrar el componente de ilegitimidad, es decir del no respeto de las leyes, que tenía el gobierno de la República en el momento del golpe del 18 de julio. Si un gobierno es ilegal ¿es lícito levantarse contra él? La respuesta,

42. El impacto de lo ocurrido en Asturias y Cataluña dentro de los sectores conservadores de la República fue fundamental, ya que observaron en ella los inicios de una revolución comunista por parte de la izquierda y, por lo tanto, el fin de lo que ellos concebían como España. Ello hizo que la polarización social aumentase y se llegase a la confrontación final en la guerra. El proceso revolucionario asturiano no ha dejado de estar presente dentro de la historiografía conservadora viéndolo como una primera fase del conflicto civil posterior cuando las izquierdas atacaron al Estado. Redundando en la búsqueda de justificaciones para el 18 de julio. S.G. Payne, El colapso de la República. Los orígenes de la Guerra Civil (1933-1936), Madrid, 2006.

43. S. Minguijón, "La cuestión española.- Antecedentes", Noticiero de España, 37, 28 de mayo de 1938.

44. M. Fernández Almagro, "El día del Caudillo", Noticiero de España, 207, 27 de septiembre de 1941.

45. J. del Rio Sainz, "Vida de un héroe”, Noticiero de España, 5, 2 de octubre de 1937. 
según los postulados de los sublevados, era evidente. Pero, ¿desde qué momento el régimen frentepopulista fue ilegítimo?, y ¿por qué? Salvador Minguijón hace referencia a que el proceso de ilegitimación del Estado Republicano provenía desde sus propios orígenes, ya que cuestionaba la viabilidad del trascendental cambio político por tan solo unas elecciones municipales. Pero, a pesar de que este pensamiento siempre estuvo presente, las premisas más duras surgieron a partir de febrero de 1936. Norman Bray Mir (militar británico residente en Mallorca) recoge en el $N d E$ su opinión acerca del Frente Popular como:

(...) un amasijo fantástico y absurdo de republicanos templados, socialistas moderados o de la rabiosa izquierda: comunistas, anarquistas, sindicalistas y marxistas», debido a que se formaron (...) turbas organizadas para el motín, dirigidas por jefes que habían aprendido la táctica terrorista en Rusia. Comenzaron los incendios, los saqueos y los asaltos a los ciudadanos de ideas opuestas a ellos. Los mítines de ideas contrarias eran interrumpidos. La intervención de la policía era nula $(\ldots)^{46}$.

Todo ello viene a justificar que la violencia fue lo que realmente condicionó el proceso electoral y su resultado. El NdE continúa con la exposición de Bray Mir para explicarlo:

(...) $\mathrm{Al}$ comenzar las elecciones, el desorden, como una marea, cubría toda España. Se procedió a la votación sin ningún control no inspecciones en los colegios. Fue así la destrucción, mutilación o sustitución de papeletas de votación (...) El terror fue tan efectivo, que millares de votantes de la derecha, hombres o mujeres, se vieron impedidos de acudir a las urnas, por miedo a la violencia personal ${ }^{47}$.

Es decir, las izquierdas volvieron al poder por la violencia que hizo que los votantes de derechas no acudiesen a votar $y$, también, por la falta de transparencia que tuvo todo el proceso, a lo que hay que añadir la «traición del gobierno de Portela Valladares» que permitió la inhibición de la policía ante los desmanes ocasionados, disolvió la Cámara y apoyó veladamente al nuevo gobierno del Frente Popular. Un argumento en el que Bray Mir coincide con palabras expuestas por Melchor Fernández Almagro ${ }^{48}$. Por tanto, concluyen exponiendo que todos los principios políticos y electorales que estaban avalados en la Constitución republicana de 1931 fueron completamente sepultados ${ }^{49}$. Pero, además, el británico también quiere soslayar la soberanía española manifestando el apoyo de la Rusia soviética a la victoria de las

46. N. Bray Mir, “Aspectos del movimiento nacional español”, Noticiero de España, 13, 27 de noviembre de 1937.

47. Bray Mir, "Aspectos del movimiento nacional...", op. cit.

48. M. Fernández Almagro, "La legitimidad del Gobierno de Valencia", Noticiero de España, 1, 4 de septiembre de 1937.

49. Para García Valdecasas los gobiernos de izquierdas fueron los que consiguieron acabar con la legitimidad política republicana porque «(...) no hubo ley que respetaran ni crimen que no cometieran. Se constituyeron voluntariamente (...) como sociedad ilegal». A. García Valdecasas, "Negocios del gobierno rojo", Noticiero de España, 23, 5 de febrero de 1938. 
izquierdas en febrero. Ello se entiende como un argumento recurrente en el periodo de la guerra por los intentos de asociar a los sublevados como los verdaderos «nacionales» y a los republicanos como unos españoles extranjerizantes.

Pabón justifica a posteriori que la base del Parlamento de Valencia, pensando ya en el contexto de la guerra, carecía de legitimidad jurídica desde sus inicios, puesto que no provenía de la victoria en las elecciones de febrero de 1936 sino en el asalto del poder que «permitió al Frente Popular amañar los primeros resultados y presidir, empleándose a fondo, la segunda vuelta; caso único en la Historia». Como consecuencia Pabón continúa con que la eficacia política quedó anulada al hacer imposible la convivencia con la oposición y las amenazas de muerte que estos recibían en el mismo pleno del Parlamento ${ }^{50}$.

Nuevamente manifiestan con claridad la cuestión de la ilegitimidad, en este caso focalizada en el Frente Popular, como argumento sobre el que poder cimentar las bases del «legítimo y responsable» levantamiento que los militares realizaron el 18 de julio.

Asimismo, otro de los problemas que ven en el Frente Popular fue que no realizó una política de «moderación», sino que, por el contrario, recuperó los «erróneos» preceptos del primer bienio republicano. Acciones que generó desconfianza en la oposición, ahondada cuando amnistiaron a los que habían promovido la revuelta de Asturias de 1934. Todo lo siguiente se dedicó a manifestar la violencia que se generó en España en aquel periodo, conflictividad de la que culpan directamente al Gobierno, sin mencionar en ningún momento a los grupos de derechas que también se dedicaban al pistolerismo.

Con todo ello el relato que querían defender era que desde febrero de 1936 la República estuvo desgobernada e inmersa en un proceso de violencia que hace válido y legítimo un intento de alzamiento contra los desmanes de la misma. Con esta situación nuevamente lo que se aportaba era una idea, del caos y la anarquía que reinaba en el periodo frentepopulista, por la que daba validez al alzamiento para poder controlar la situación ${ }^{51}$.

En el desprestigio del concepto de democracia que tenía la República los autores van atacar lo que se vivía en las sesiones parlamentarias como un reflejo de la violencia latente en la sociedad española. En las páginas del $N d E$ las referencias que se hacen a esta dialéctica entre las diferentes tendencias políticas solo estaba enfocada a los ataques que desde el Frente Popular se hacia los sectores conservadores del hemiciclo con claras amenazas a los principales dirigentes de la derecha como José María Gil-Robles o José Calvo Sotelo. Aunque fueron las insinuaciones hechas a este segundo las que mayor recorrido tuvieron entre los periodistas afines del bando sublevado y que, evidentemente, también fueron expuestas por el NdE. Conocidos eran los enfrentamientos que Calvo Sotelo tuvo con Casares Quiroga, con Valentín Galarza (del cual recoge el NdE que había comentado que «tratándose de Calvo Sotelo el atentado es lícito y plausible») o con Dolores Ibárruri (que supuestamente comentó en una de sus disputas parlamentarias «este hombre ha hablado por última vez» ${ }^{52}$ ).

50. J. Pabón, "Otra vez las Cortes. El caso Portela Valladares", Noticiero de España, 6, 9 de octubre de 1937. 51. S. Minguijón, "El alzamiento era inevitable”, Noticiero de España, 51, 3 de septiembre de 1938.

52. A. Palacio, "Hombres de España: Calvo Sotelo y Onésimo Redondo", Noticiero de España, 111, 18 de noviembre de 1939. 
Pero lo más grave de este último caso fue la conclusión que tuvo, puesto que vino a justificar definitivamente para una parte conservadora de la sociedad que el gobierno no miraba por las garantías de los ciudadanos, ni siquiera de los políticos que la representaban. El asesinato de José Calvo Sotelo ${ }^{53}$ la madrugada del 13 de julio de 1936 fue calificado por la prensa nacionalista como un verdadero «crimen de Estado», no obstante, en ningún momento se hace relación a la muerte de Calvo Sotelo con la del teniente Castillo. Para el relato del trágico final que tuvo el jefe de la oposición, el $N d E$ utilizó la declaración que hizo uno de los que aquella noche iban en la camioneta: el guardia de asalto Aniceto Castro Piñeiro. Este había sido hecho prisionero en las trincheras del frente de Madrid y cuando tuvieron conocimiento de su participación en el asesinato fue trasladado al campo de concentración de Talavera de la Reina donde prestó declaración. La versión que aporta de los hechos fue que la orden para acabar con Calvo Sotelo partió del Director General de Seguridad, José Alonso Mallol, a su vez mandado por el ministro de la Gobernación, Juan Molés Ornella, siendo presidente del Consejo de Ministros Santiago Casares Quiroga ${ }^{54}$. Es decir, con todo ello y, además, con la declaración del guardia de asalto lo que quería hacer desde los servicios de prensa y propaganda de la España de Franco era relacionar la muerte de Calvo Sotelo con una orden directa desde instancias del Gobierno de la República. Idea que fue la que definitivamente motivó el alzamiento. Como se puede comprobar la historiografía del régimen usó con profusión esta de idea del asesinato de Calvo Sotelo como el casus belli olvidando las gestiones que desde hacía meses venían haciendo algunos sectores militares y civiles para destruir a la República y lo que esta significaba.

La denuncia de toda la violencia durante el periodo republicano supuso, como afirma González Calleja, una de las bases legitimadoras sobre las que fue asentando el franquismo. Para ello era importante el conectar toda la violencia perpetrada en el periodo del Frente Popular e incluso anterior, con los desmanes y persecuciones realizados en la zona republicana ${ }^{55}$.

Con ello lo que se quiere defender era que la guerra civil no era una lucha de idearios políticos, sino un levantamiento nacional contra un gobierno que se degeneró en anarquía y revolución. Incluso recogen la referencia de que el Gobierno republicano estaba preparando un golpe definitivo contra su propia República cuando buscó el apoyo de la Rusia soviética para imponer un régimen de carácter comunista. Nuevamente se aprecia aquí los intentos de relacionar a la República con la Unión Soviética y el comunismo y la consecuencia influencia

53. En los diferentes artículos que se dedican a la figura de Calvo Sotelo en el $N d E$ destacan su función de estadista, la buena gestión que desarrolló en el Ministerio de Hacienda durante la Dictadura de Primo de Rivera, su ferviente oposición a la República, etc. Debido a esta trágica muerte el Franquismo lo tuvo en su memoria como uno de los que dieron su vida, con nobleza, por salvar a España de la decadencia. Por ello, anualmente se conmemoraba su fallecimiento con misas tanto en Madrid como en otras ciudades con la idea de rendir honores a uno de los primeros mártires de la causa nacional. En las páginas del $N d E$ son varios los artículos y homenajes que se dedican a Calvo Sotelo.

54. A. Reverte, "Calvo Sotelo, asesinado por el gobierno del Frente Popular en vísperas de la guerra", Noticiero de España, 62, 19 de noviembre de 1938.

55. E. González Calleja, Cifras cruentas. Las víctimas mortales de la violencia sociopolítica en la Segunda República española (1931-1936), Granada, 2015, 20-27. 
extranjerizante en los dirigentes que llevaron a España a la ruina. Para ellos, el golpe estaba enmascarado por las Olimpiadas Populares que se celebraban en Barcelona a finales de julio de 1936, en concreto, preparado para el 31 de julio. El argumento de este apoyo ruso viene determinado por el hecho de que el país soviético estaba dando armas y enviaba mercenarios a España, que entraban por la frontera francesa, para tener un destacamento de carácter militar que apoyase el alzamiento ${ }^{56}$. Por tanto, los diferentes autores se aventuran a exponer que el 18 de julio se manifestó como un contrapunto a esa sublevación comunista.

El Frente Popular era el regreso a las políticas que tanto habían denostado en el primer bienio de Azaña. Por lo tanto, con el leve lapso de tiempo de los gabinetes de Lerroux nuevamente los autores del $N d E$ vienen a atacar las bases de lo que representaba la República enlazándolo con la latente violencia social existente. Para darle un mayor sentido a su relato va a obviar noticias como la participación falangista en el pistolerismo, las declaraciones también altisonantes de la oposición en el Parlamento o, lo peor, los preparativos que Mola ya estaba haciendo para el golpe de estado desde marzo de 1936. Por lo tanto, si se une caos, anarquía, una posible revolución, la connivencia del gobierno con la violencia, los ataques a la religión, los asesinatos de opositores políticos, las afrentas a la autoridad, etc., los sectores conservadores vieron como legítimo un alzamiento que cambiase el rumbo de España. Había que salvar a la Patria, redimirla de los «pecados»y, además, informar al exterior de todo ello como justificación de la guerra que se estaba desarrollando en suelo español ${ }^{57}$.

\subsection{La República durante la Guerra: la caída}

El estallido del conflicto fue el punto de arranque de una doble legalidad en España, dada la presencia de dos estados actuantes sobre los españoles ${ }^{58}$. La legítima República se veía asediada tanto por los militares como por los problemas internos que tenía. Los sublevados fueron creando su Estado a medida que avanzaba el conflicto. Por lo tanto, viendo esa dicotomía continuaron aportando argumentos en el contexto tanto nacional como internacional para alegar finalmente que la República en la guerra no representaba a ninguna democracia y que continuaba realizando acciones que incidían en su ilegitimidad.

De este modo, la propaganda franquista continuó repitiendo hasta la saciedad una doble falsedad de los poderes actuantes en el Gobierno Republicano: por un lado, la mencionada ilegitimidad de origen basada en las elecciones de febrero de 1936 y su derivado periodo

56. N. Bray Mir, "Aspectos del movimiento nacional español”, Noticiero de España, 13, 27 de noviembre de 1937.

57. Para Fernando Puell de la Villa los datos de la violencia del periodo de Frente Popular no tuvo incidencia en la trama golpista del 18 de julio ya que esta se había puesto en marcha antes de la agravación de la situación política. F. Puell de la Villa, "La trama militar de la conspiración”, F. Sánchez (coord.), Los mitos del 18 de julio, Barcelona, 2013, 77.

58. Para ampliar el conocimiento de la guerra desde una perspectiva de la política e influencia en la República es imprescindible la trilogía de A. Viñas La soledad de la República (Barcelona, 2006), El escudo de la República (Barcelona, 2007) y El honor de la República (Barcelona, 2010). 
de violencia; y, por otro lado, una ilegitimidad de las Cortes, ya en la guerra, a consecuencia de la configuración que va a tomar el gobierno republicano en el conflicto bélico.

Esta segunda ilegitimidad del Gobierno Republicano se basaba en que alegaban que había suplantado las instituciones republicanas en medio de la guerra y de la revolución comunista. Por lo tanto, las instituciones democráticas republicanas no existían de hecho ni de derecho ya que había perdido la virtud jurídica, la eficacia política y su existencia material. Así, al desprestigio del Parlamento derivado del periodo anterior, ahora, en el contexto de la guerra añade la idea de falta de representatividad de las diferentes tendencias políticas y, por lo tanto, nuevamente incumple la Constitución de 1931. La cuestión se fundamentaba en la pérdida de diputados que la Cámara había sufrido por diversas circunstancias. Melchor Fernández Almagro enumera los motivos de estas ausencias: la principal que argüía era que muchos de los diputados habían huido por miedo a posibles represalias a la «zona liberada»; dentro de estos huidos también añade a ellos a los habían emigrado fuera de España o los que manifestaron públicamente su apoyo a Franco. Asimismo, también añade que la diversidad política del Parlamento también se había perdido a causa de los «crímenes de retaguardia» que el gobierno realizó contra los enemigos políticos, dado que una vez abierta la veda con el asesinato de Calvo Sotelo, los siguientes vinieron por sí solos, destacando algunos como Melquíades Álvarez, Manuel Rico Avelló, José María de Albiñana, etc. En total más de treinta personas las asesinadas, según el NdE, por el gobierno o por las milicias sin procedimiento judicial alguno. Ajusticiados que incidieron en una nula representatividad de la oposición en el Parlamento ${ }^{59}$. Con toda esta exposición a la conclusión que quieren acercar a los lectores es que, ante las bajas, por los motivos expuestos el Parlamento había perdido el poder representativo de toda la Nación, por lo tanto, concluye que «(...) la República ha traicionado el espíritu nacional».

Asimismo, el propio devenir del conflicto bélico aportó nuevos argumentos que repercutían en la imagen del Parlamento republicano y que los sublevados potenciaron en sus medios propagandísticos. Por ejemplo, alega que la conquista de España que estaban realizando los ejércitos de Franco contribuían a ahondar en el desprestigio del Parlamento dado que cada vez venían representando a menos personas y que muchos de los parlamentarios pertenecían a circunscripciones electorales que ya no estaban representadas en el territorio republicano por lo que eso significaba que habían perdido la legitimidad. Por lo tanto, Fernández Almagro lo que comentaba era que la República mantenía las apariencias parlamentarias solamente para querer conservar los apoyos en el exterior ${ }^{60}$.

Pero, además, dentro de este núcleo republicano también van a manifestar las constantes disputas internas, es decir, la desunión, de los mismos tanto en la política como en la propia gestión de la guerra. Todo ello marcándolo con un claro contraste acerca de la imagen de unión que se expone de los militares alzados, sobre todo con la escenificación de unidad manifestada con la Jefatura del Estado en octubre de 1936 y, posteriormente, la política con el Decreto de Unificación el 19 de abril de 1937.

59. M. Fernández Almagro, "La legitimidad del gobierno de Valencia", Noticiero de España, 1, 4 de septiembre de 1937.

60. Fernández Almagro, "La legitimidad del gobierno de Valencia”, op. cit. 
Las acciones del Gobierno republicano también fueron criticadas. El abandono de la capital en dirección a Valencia, en noviembre de 1936, también contribuyó a la deslegitimación de la República. Ahondando posteriormente por el segundo traslado a Barcelona, 31 de noviembre de 1937. Melchor Fernández Almagro justifica que este cambio de residencia del gobierno, al cual denomina directamente como «Comité Revolucionario», vino motivado, a parte de las causas bélicas, a que la ciudad Condal tenía el clima social y político idóneo para los republicanos. Había sido «(...) la capital de la revolución antinacional» y lugar donde había fuerzas disgregadoras y subversivas que estaban siempre al acecho contra la verdadera y tradicional España ${ }^{61}$.

Desde este momento la suerte ya estaba echada, puesto que los repliegues hacia Francia mostraron un importante signo de debilidad del Gobierno republicano frente a los avances de las fuerzas sublevadas en los frentes de guerra. El 1 de febrero de 1939 las Cortes republicanas se reunieron por última vez en Figueras. A esta reunión solo asistieron unos sesenta diputados, hechos que contribuyeron a su desprestigio, puesto que representaba definitivamente un Gobierno fantasma. El Gobierno republicano cruzó la frontera francesa el 4 de febrero de 1939, hecho que los propagandistas sublevados tradujeron como una expulsión por parte del Ejército de Franco dado que habían presionado militarmente Cataluña. La huida a Francia del Gobierno fue interpretada como la «(...) última sombra de régimen de derecho y de poder político que los interesados en informarse mal pudiesen atribuirles todavía» ${ }^{62}$. Es decir, este hecho despojó definitivamente al Gobierno republicano de toda autoridad y poder. Las últimas acciones de Negrín no fueron tenidas en cuenta por la falta de poder que tenían para oponerse a la victoria del ejército de Franco.

La conclusión que la prensa y propaganda del $N d E$ extrajo de todo el periodo republicano y de la guerra que han desarrollado la resume Melchor Fernández Almagro de la siguiente manera:

(...) a) que la República fue un régimen de corrupción, insuperable egoísmo, terribles rivalidades, criminales violencias, desorganización absoluta; b) que la guerra fue provocada por el Frente Popular y que el fementido régimen que trató de aprovecharse de ella, lejos de ser un régimen liberal y democrático, como mentía su propaganda, estaba controlado por el comunismo recibía ayudas antinacionales, y obraba a beneficio del poder de Negrín; c) que las fuerzas armadas de la República eran forzadas a pelear, mientras sus dirigentes estaban en el secreto de la derrota que les aguardaba, siendo la propaganda falsa a sabiendas, y d) que el oro y caudales de varia índole robados a España, constituyen el botín que se vienen disputando los antagonistas ${ }^{63}$.

A parte del análisis político de la situación de la República durante la guerra existen otros factores que los propagandistas del bando nacional explotaron en todo momento para justificar su victoria por las armas. El creciente peso del sindicalismo en la lucha, los problemas entre las diferentes tendencias de izquierdas o la influencia de la Rusia Comunista en

61. Fernández Almagro, "La legitimidad del gobierno de Valencia", op. cit.

62. M. Fernández Almagro, "Ni sombra del gobierno rojo", Noticiero de España, 75, 18 de febrero de 1939.

63. Fernández Almagro, "Ni sombra del gobierno rojo", op. cit. 
España fueron argumentos válidos para perdurar tanto en la guerra como en la posterior paz. De todo ello, fue la influencia soviética el peor de los aspectos analizados por la propaganda, ya que venía a corroborar la entrada e injerencia del comunismo en España. Aquí, evidentemente lo que también desarrollaron fue la omisión de la verdadera influencia que la Italia de Mussolini y la Alemania de Hitler tuvieron en el conflicto y en la creación de la Dictadura.

Con estos argumentos del peso comunista en la dirección de la guerra lo que querían demostrar era que quien realmente tomaba las decisiones del gobierno Republicano no era el propio gobierno sino la mano de Stalin era la que coordinaba la política comunista en el mundo ${ }^{64}$. El ejemplo que el $N d E$ recoge para justificar la intromisión estalinista en España es bastante llamativo. Puesto que se van a apiadar del POUM, caracterizado por el trotskismo, en actos como el asesinato de Andrés Nin o la expulsión de los concejales de este partido del ayuntamiento de Valencia. Para ellos, estos hechos demuestran el «largo brazo» del comunismo que quiere acabar con todo foco de oposición en cualquier lugar donde esté presente:

(...) el trotskismo ha sido declarado fuera de la ley [en la URSS], en durísimos términos atestiguados por destierros, matanzas y aún consignas que traspasan las fronteras, para hacer llegar al último rincón del mundo, el anatema, cuando no la muerte, sobre el trotskismo, con Trotsky, en primer lugar, naturalmente ${ }^{65}$.

Por otro lado, aporta el argumento de las disensiones internas dentro de la República era una muestra recurrente, sobre todo, en contraposición a la unidad que manifiesta el bando sublevado. Las rivalidades dentro del Partido Socialista, y también en el gobierno, de personajes como Largo Caballero e Indalecio Prieto eran, para la propaganda autodenominada nacional, una muestra inequívoca de las disputas internas en la República, lo que demuestra que no tenía la suficiente fuerza y unidad para enfrentarse a un movimiento unido, español y con valores como el que demuestra el bando sublevado.

Finalmente, lo que la propaganda sublevada cuestionaba era el verdadero patriotismo que tenía la República. El argumento recurrente era que a pesar de las muestras de «españolidad» del gobierno republicano ese nacionalismo era falso debido a que estaba basado en una doble mentira: por un lado, porque le República cedía soberanía a los rusos en la toma de las decisiones (

64. Relacionar el comunismo con la República fue una de las premisas que más potencialidad tuvo. Por lo tanto, relacionar a Stalin con lo que ocurría en España era primordial, más si cabe con los apoyos en foros internacionales que los comunistas hacían a la República, ante la indefensión que la dejaron las democracias internacionales, y con la presencia en la Brigadas Internacionales de voluntarios y comisarios políticos. El asociar todos estos conceptos con la República ha estado presente en la historiografía conservadora hasta la más reciente actualidad. Para ampliar el conocimiento acerca de la influencia soviética en la Guerra Civil española se puede consultar: D. Kowalsky, La Unión Soviética y la Guerra Civil española: una revisión crítica, Barcelona, 2004.

65. M. Fernández Almagro, "Enfeudamiento de la España roja”, Noticiero de España, 20, 15 de enero de 1938.

Revista de historiografía 29, 2018, pp. 229-251 
cambio de dinero que apoyan este argumento ${ }^{66}$ ) demostrando esa falta de sentimiento patrio. En contra, para la España que representaba el general Franco la cuestión de la soberanía del Estado era un aspecto completamente incuestionable. Por otro lado, los problemas de los diferentes partidos del gobierno republicano demostraban que estos tenían más arraigado un «patriotismo de partido» que el verdadero patriotismo que ha de defender a la nación ${ }^{67}$. Esta segunda afirmación llega a exponer la idea de que la República representa el antipatriotismo o lo que es igual que representa a la Anti-España. Minguijón marcaba claramente esa dicotomía que representaban para él a la nueva España respecto de la antigua República: «(...) plenamente su fecundidad, su fuerza creadora, su virtualidad para engendrar abnegaciones, sacrificios, heroísmo, disciplina», frente a otros que han demostrado la descomposición de valores que conllevaban ${ }^{68}$.

El 1 de abril de 1939 finalizada la guerra la prensa y propaganda, ya influenciada por Serrano Suñer, continuó la campaña de prestigio hacia el nuevo Estado que se estaba formando y ahondar en el descrédito de la República para alabar la paz alcanzada y fundamentar una nueva grandeza para España.

\section{Conclusiones: no había que olvidar lo que la República significó}

Los autores del $N d E$ tuvieron presente lo que la República había significado para España hasta su último número el 4 de octubre de 1941. Dado que, aunque no se hacían artículos de análisis concreto del periodo anterior, siempre se encontraban manifestaciones despectivas respecto a la misma, ya que había que rememorar constantemente lo que República había significado para España como medio para no olvidar el sino del nuevo Estado que se estaba formando bajo la mano del «victorioso» general Franco.

Así, el bando sublevado utilizó todos sus recursos propagandísticos, entre los que se encontraba el $N d E$, con el objetivo de crear una imagen despectiva y deslegitimada de la Segunda República. Para ello, la utilización de las técnicas propagandísticas, que se han mencionado a lo largo del trabajo, fueron fundamentales en el afianzamiento y difusión de las ideas en los sectores que adquirían las publicaciones donde se difundía el NdE. Así, este argumentario contribuyó, junto con otros medios de la Prensa y Propaganda, a la construcción de un relato acerca de la República que la historiografía franquista mantuvo vigente durante mucho tiempo en el imaginario colectivo.

En todo ello, también hay que destacar la importancia del lenguaje que los autores del $N d E$ utilizaron. Quizá estos no fueron muy conocidos en los años de vigencia del $N d E$, pero sin duda fueron personas de un importante nivel intelectual los cuales pusieron su plu-

66. García Valdecasas recoge que la República ofrece a cambio de un empréstito de la Banca francesa la riqueza y el valor de las minas de mercurio de Almadén y las de potasa de Lérida. A. García Valdecasas, "Negocios del gobierno rojo", Noticiero de España, 23, 5 de febrero de 1938.

67. M. Fernández Almagro, "Enfeudamiento de la España roja”, Noticiero de España, 20, 15 de enero de 1938.

68. S. Minguijón, “Ideas triunfantes”, Noticiero de España, 85, 29 de abril de 1939. 
ma a favor de la propaganda nacional. En este sentido, se aprecia la dicotomía de términos positivo-negativo cuando tienen que hacer referencia comparativa a los dos Estados que se encontraban en el conflicto. Por ejemplo, la idea de construcción siempre fue asociada al bando sublevado para asociarlos a la formación y reconstrucción de un Estado que había sido aniquilado y destruido por la República. Pero no solo en estas directrices, también usando calificativos despectivos como el de «rojos», sin hacer mera distinción entre las diferentes tendencias política del republicanismo, todos eran asociados como asesinos, ladrones, saqueadores y traidores a la Patria, mientras que el «verdadero español», el que defendía lo que Franco había llevado a las armas, no tenía duda de que el ejército hacía lo correcto y defendía los valores de la España católica. Todos estos mensajes eran importantes con la idea de deformar la figura del enemigo republicano.

Por último, en el análisis que se hace de la propia gestión de la República dejó muchos temas sin analizar y que, evidentemente, también eran importantes para comprender la polarización social existente en España durante aquellos años. Aspectos como la Sanjurjada, los preparativos del golpe de Estado o el pistolerismo falangista fueron completamente obviados dado que rompía con el relato que querían imponer. Todo se fundamentaba en la necesidad de aportar legitimidad a los militares alzados el 18 de julio. 